\title{
Effect of Frailty on Outcome after Traumatic Spinal Cord Injury
}

\author{
Dan Banaszek,, Tom Inglis,, Travis E. Marion, ${ }^{2}$ Raphaële Charest-Morin,, Eryck Moskven, ${ }^{1}$ Carly S. Rivers, ${ }^{3}$ \\ Dilnur Kurban, ${ }^{3}$ Alana M. Flexman, ${ }^{4,5}$ Tamir Ailon, ${ }^{6}$ Nicolas Dea, ${ }^{6}$ Brian K. Kwon, ${ }^{1,7}$ Scott Paquette, ${ }^{6}$ \\ Charles G. Fisher, ${ }^{1}$ Marcel F. Dvorak, ${ }^{1,7}$ and John T. Street ${ }^{1,7}$
}

\begin{abstract}
Frailty negatively affects outcome in elective spine surgery populations. This study sought to determine the effect of frailty on patient outcome after traumatic spinal cord injury (tSCI).

Patients with tSCI were identified from our prospectively collected database from 2004 to 2016. We examined effect of patient age, admission Total Motor Score (TMS), and Modified Frailty Index (mFI) on adverse events (AEs), acute length of stay (LOS), in-hospital mortality, and discharge destination (home vs. other). Subgroup analysis (for three age groups: $<60,61-75$, and 76+ years), and multi-variable analysis was performed to investigate the impact of age, TMS, and mFI on outcome. For the 634 patients, the mean age was 50.3 years, $77 \%$ were male, and falls were the main cause of injury (46.5\%). On bivariate analysis, $\mathrm{mFI}$, age at injury, and TMS were predictors of AEs, acute LOS, and in-hospital mortality. After statistical adjustment, mFI was a predictor of LOS ( $p=0.0375)$, but not of AEs $(p=0.1428)$ or in-hospital mortality $(p=0.1245)$. In patients $<60$ years of age, mFI predicted number of AEs, acute LOS, and in-hospital mortality. In those aged 61-75, TMS predicted AEs, LOS, and mortality. In those 76+ years of age, mFI no longer predicted outcome.

Age, $\mathrm{mFI}$, and TMS on admission are important determinants of outcome in patients with tSCI. mFI predicts outcomes in those $<75$ years of age only. The inter-relationship of advanced age and decreased physiological reserve is complex in acute tSCI, warranting further study. Identifying frailty in younger patients with tSCI may be useful for peri-operative optimization, risk stratification, and patient counseling.
\end{abstract}

Keywords: aging; deficit; frailty; prognosis; spinal cord injury

\section{Introduction}

$\mathbf{I}$ N THE MEDiCAL LITERATURE, the term frailty is defined as "a state of decreased physiologic reserve, with increased susceptibility to external stressors." 1 This concept has previously been identified as independent from chronological age in terms of patient outcomes. ${ }^{2}$ Its association with poor outcomes has been demonstrated in multiple settings, from the community dwelling population to the surgical population. ${ }^{3-10}$ This relationship appears particularly relevant in patients requiring emergent procedures. ${ }^{11,12}$ In a recent systematic review of the spine surgery literature, frailty has been demonstrated to affect post-operative outcomes such as adverse events (AEs), mortality, and length of stay (LOS). ${ }^{13}$
Although the concept of frailty has been largely accepted, its operational definition is less clear. In most of the spinal literature, the Modified Frailty Index (mFI) has been used as a surrogate measure of frailty. The $\mathrm{mFI}$, a simplified version of the Canadian Study of Health and Aging Frailty Index, is based on the theory of "accumulating deficits." The mFI includes 11 variables relating to pre-injury deficits including functional independence and 10 comorbid medical conditions. ${ }^{14,15}$

To our knowledge, the concept of frailty has never been applied to a newly injured (or acute) traumatic spinal cord injury (tSCI) population. Although typically occurring most frequently in younger males from motor vehicle or sports injury, in tSCI there is an epidemiological shift in the population relating to aging "baby

\footnotetext{
${ }^{1}$ Vancouver Spine Surgery Institute, Department of Orthopaedics, University of British Columbia, Vancouver, British Columbia, Canada.

${ }^{2}$ Division of Orthopaedic Surgery, Northern Ontario School of Medicine, Thunder Bay, Ontario, Canada.

${ }^{3}$ Rick Hansen Institute, Vancouver, British Columbia, Canada.

${ }^{4}$ Department of Anesthesiology, Pharmacology, and Therapeutics, University of British Columbia, Vancouver, British Columbia, Canada.

${ }^{5}$ Department of Anesthesiology and Perioperative Care, Vancouver General Hospital, Vancouver, British Columbia, Canada.

${ }^{6}$ Vancouver Spine Surgery Institute, Division of Neurosurgery, Department of Surgery, University of British Columbia, Vancouver, British Columbia, Canada.

${ }^{7}$ International Collaboration on Repair Discoveries (ICORD), Faculty of Medicine, University of British Columbia, Vancouver, British Columbia, Canada.
} 
boomers" that has increased the average age at injury. ${ }^{16,17}$ By 2032, the greatest proportion of new $\mathrm{tSCI}$ is predicted to be in patients over 70 years of age, with an estimated $46 \%$ of the newly injured being over the age of 60 years. ${ }^{18}$

Injuries in the elderly are most often incurred by falls from a standing height, which may be exacerbated by age-related degenerative disc disease. Older individuals are physiologically less able to improve functional recovery even in the presence of neurological recovery, ${ }^{18-20}$ with recovery being complicated by a higher rate of pre-existing conditions, ${ }^{21,22}$ including degenerative disc disease, and susceptibility to secondary health conditions such as pneumonia and pressure injury. ${ }^{23,24}$ The clinical management of older individuals with new tSCI provides a challenge for clinicians, evidenced by a previous study in which older patients were operated on less frequently, and at a longer interval from admission. ${ }^{16}$ Whereas clinical decision-making involves a subjective assessment of risk of poor outcomes with consideration of the overall accumulation of deficit, assessment of frailty would assist in clinical decision-making and risk management.

The objectives of this study were therefore to: 1 ) describe patient characteristics associated with frailty, and 2) examine the effect of frailty on post-operative outcomes in terms of in-hospital mortality, in-hospital LOS, and in-hospital AEs in a cohort of newly injured tSCI patients.

\section{Methods}

\section{Study design} data.

Our study is a retrospective cohort of prospectively collected

\section{Study population}

The analysis cohort comprised individuals with new tSCI admitted for acute care at a Level 1 trauma, quaternary referral center and enrolled in the Rick Hansen Spinal Cord Injury Registry (RHSCIR), a multi-center, Canadian, prospective, observational registry of adults with new tSCI; full details have been described elsewhere. ${ }^{25}$ Research Ethics Board (REB) approval was obtained. Study subjects included patients with tSCI injured between 2004 and 2016 who received acute treatment at the study site.

\section{Demographics}

Age, gender, and body mass index (BMI) were obtained.

\section{Medical comorbidities}

Medical comorbidities at the time of injury were assessed by both the Charlson Comorbidity Index (CCI) and Elixhauser Comorbidity Index (ECI), commonly used indexes that are normally calculated from administrative data codes. ${ }^{26,27}$ A total count of comorbidities was also obtained.

\section{Frailty}

The $\mathrm{mFI}$ as introduced above includes a question regarding functional independence, and the following medical comorbidities: diabetes mellitus, lung problems, congestive heart failure, myocardial infarction, cardiac problems, hypertension, impaired sensorium, prior transient ischemic attack, history of stroke, and peripheral vascular disease. The number of deficits present divided by 11 gives the $\mathrm{mFI}$ score, providing an index with a range of 0 to 1 . The mFI was calculated by chart review for assessment of functional status, and comorbid conditions as collected in the RHSCIR. Patients were categorized as not frail $(\mathrm{mFI}=0)$, pre-frail $(0<\mathrm{mFI}$
$<0.21$ ), and frail ( $\mathrm{mFI} \geq 0.21)$ based on previous data. ${ }^{28}$ Comparison of patient groups was also categorized as non-frail $(\mathrm{mFI}<0.21)$ and frail ( $\mathrm{mFI} \geq 0.21)$ for analysis purposes.

\section{Injury mechanism}

Injury mechanism is ecorded as: assault, fall, sport, transport, or other. $^{29}$

\section{Neurological severity and level}

Neurological classification was measured at admission and discharge with the International Standards of Neurological Classification of Spinal Cord Injury (ISNCSCI), ${ }^{30}$ including neurological severity (American Spinal Injury Association [ASIA] Impairment Scale [AIS]; A/B/C/D), level of injury (high cervical C1-C4; low cervical C5-T1; thoracic T2-T10; thoracolumbar T11-S5), and Total Motor Score (TMS; out of 100).

\section{Outcome measures}

Primary study outcome variables included in-hospital patient mortality, acute hospital LOS, and number of AEs during hospital stay. Secondary outcomes included patient characteristic differences between cohorts and discharge destination (home vs. other). AEs were obtained from the previously validated Spinal AdVerse Events System (SAVES2) database at our institution and is used to identify and record acute care AEs on all spine patients including those with tSCI. AE data are recorded through a rigorous prospective systematic process previously described. ${ }^{31,32}$ The top five and total number of AEs from SAVES2 were also explored.

\section{Statistical analysis}

Descriptive statistics were used to describe the demographics and injury characteristics of the cohort. Participant characteristics were compared between those deemed as frail and not frail by mFI to determine if there is significant difference between these two groups of participants. The comparison was made using either $t$ test or Wilcoxon rank sum test for normally distributed versus non-normally distributed continuous variables, respectively. Comparisons between two categorical variables were assessed using a chi-square test (or Fisher's exact test if the expected cell counts were five or less). Pearson correlations were obtained to examine linear relationship between mFI, age at injury, and TMS at admission with three primary outcomes of interest. Age was selected due to an observed complex relationship between age and $\mathrm{mFI}$, whereas TMS was used to minimize the risk of confounding in terms of patient outcome. These associations were re-examined in multi-variable analysis after adjusting for relevant covariates. Goodness-of-fit tests were performed for all models. Associations with a $p$-value $<0.05$ were considered statistically significant. All analyses were performed using SAS software, version 9.4 of the SAS System for Windows ${ }^{\circledR} 2013$ (SAS Institute, Inc., Cary, NC).

\section{Results}

\section{Patient characteristics}

A total of 634 patients with tSCI were identified in our database during the study period. The most common mechanism of injury was falls $(295,46.5 \%)$. Neurological injury showed AIS Grade A to be the most common $(245,39.1 \%)$, followed by AIS D (206, $32.9 \%)$, AIS C $(123,19.7 \%)$, and AIS B $(52,8.3 \%)$. Most patients presented with either high (C1-C4, 237, 37.4\%) or low (C5-T1, $230,36.3 \%$ ) cervical injuries. The remainder of characteristics are summarized in Table 1. 
Table 1. Patient Characteristics for the Analysis Cohort $(N=634)$ and the Frail $(\mathrm{mFI}>0.21 ; N=76)$ AND NON-FraIL (MFI $\leq 0.21 ; N=353)$ COHORTS

\begin{tabular}{|c|c|c|c|c|}
\hline Variable & Analysis cohort, $\mathrm{n}=634$ & Frail cohort, $\mathrm{n}=76$ & Non-frail cohort, $\mathrm{n}=353$ & $\mathrm{P}$-value \\
\hline Age at injury (years); mean (SD) & $50.3(19.8)$ & $70.6(11.0)$ & $42.0(17.5)$ & $<0.0001$ \\
\hline Male, $n(\%)$ & $488(77.0)$ & $59(77.6)$ & $275(77.9)$ & 0.9587 \\
\hline BMI, mean (SD) & $25.2(4.3)$ & $27.3(4.2)$ & $24.6(4.0)$ & $<0.0001$ \\
\hline Mechanism of injury, $n(\%)$ & & & & $<0.0001$ \\
\hline Falls & $295(46.5)$ & $56(73.7)$ & $112(31.7)$ & \\
\hline Transport & $160(25.2)$ & $13(17.1)$ & $97(27.5)$ & \\
\hline Sports & $134(21.1)$ & $3(3.9)$ & $113(32.0)$ & \\
\hline Other & $45(7.1)$ & $4(5.3)$ & $31(8.8)$ & \\
\hline Neurological severity of injury (AIS), $n(\%)$ & & & & 0.2410 \\
\hline A & $245(39.1)$ & $24(32.0)$ & $156(44.6)$ & \\
\hline $\mathrm{B}$ & $52(8.3)$ & $6(8.0)$ & $27(7.7)$ & \\
\hline $\mathrm{C}$ & $123(19.7)$ & $16(21.3)$ & $61(17.4)$ & \\
\hline $\mathrm{D}$ & $206(32.9)$ & $29(38.7)$ & $106(30.3)$ & \\
\hline Neurological level of injury, $n(\%)$ & & & & 0.0002 \\
\hline High cervical $(\mathrm{C} 1-\mathrm{C} 4)$ & $237(37.4)$ & $39(51.3)$ & $116(32.9)$ & \\
\hline Low cervical (C5-T1) & $230(36.3)$ & $30(39.5)$ & $127(36.0)$ & \\
\hline Thoracolumbar (T2-S5) & $167(26.3)$ & $7(9.2)$ & $110(31.2)$ & \\
\hline Total Motor Score admission, mean (SD) & $46.6(31.2)$ & $41.8(30.1)$ & $47.9(31.5)$ & 0.1529 \\
\hline Charlson Comorbidity Index, mean (SD) & $0.6(1.1)$ & $2.1(1.4)$ & $0.2(0.6)$ & $<0.0001$ \\
\hline Elixhauser Comorbidity Index, mean (SD) & $1.0(1.1)$ & $1.8(1.2)$ & $0.5(0.8)$ & $<0.0001$ \\
\hline mFI, mean $(\mathrm{SD})$ & $0.1(1.1)$ & $0.3(0.1)$ & $0(0.0)$ & $<0.0001$ \\
\hline Count of comorbidities, $n(\%)$ & & & & $<0.0001$ \\
\hline None & $180(47.4)$ & $1(2.0)$ & $152(73.8)$ & \\
\hline $1-2$ & $155(40.8)$ & $23(45.1)$ & $52(25.2)$ & \\
\hline $3+$ & $45(11.8)$ & $27(52.9)$ & $2(1.0)$ & \\
\hline \multicolumn{5}{|l|}{ Top 3 comorbidities; $n(\%)$} \\
\hline Diabetes & $52(13.7)$ & $26(51.0)$ & $2(1.0)$ & $<0.0001$ \\
\hline Osteo/degenerative arthritis & $23(6.1)$ & $3(5.9)$ & $6(2.9)$ & 0.3873 \\
\hline Any malignancy & $20(5.3)$ & $7(13.7)$ & $6(2.9)$ & 0.0016 \\
\hline \multicolumn{5}{|l|}{ Top 5 adverse events, $n(\%)$} \\
\hline UTI & $273(43.1)$ & $31(40.8)$ & $151(42.8)$ & 0.6576 \\
\hline Pneumonia & $267(42.1)$ & $39(51.3)$ & $137(38.8)$ & 0.0463 \\
\hline Neuropathic pain & $259(40.9)$ & $29(38.2)$ & $159(45.0)$ & 0.2053 \\
\hline Cardiac arrest/failure/arrythmia & $143(22.6)$ & $25(32.9)$ & $76(21.5)$ & $\mathbf{0 . 0 3 7 3}$ \\
\hline Delirium & $136(21.5)$ & $32(42.1)$ & $51(14.4)$ & $<.0001$ \\
\hline
\end{tabular}

Bold indicates statistical significance.

AIS, American Spinal Injury Association (ASIA) Impairment Scale; BMI, body mass index; IQR, inter-quartile range; mFI, Modified Frailty Index; $\mathrm{SD}$, standard deviation; UTI, urinary tract infection.

\section{Frailty distribution}

Table 2 reports frailty status by age group $(<60,61-75,76+$ years); percentage of frail individuals by age group was $2.8 \%$, $27.9 \%$, and $35.6 \%$, respectively. For those aged 61 or older, $30.6 \%$ were deemed frail. We noted a complex relationship between frailty and age (Fig. 1). When analyzed as median $\mathrm{mFI}$ versus age,

Table 2. Frailty Status by Age Group: Frail $(\mathrm{mFI}>0.21)$, Pre-Frail $(0<\mathrm{MFI}<0.21)$, AND NON-FraIL $(\mathrm{MFI}=0)$

\begin{tabular}{lcccr}
\hline $\begin{array}{l}\text { Frailty } \\
\text { status }\end{array}$ & $\begin{array}{c}<0 \text { years, } \\
\mathrm{n}=425\end{array}$ & $\begin{array}{c}61-75, \\
\mathrm{n}=136\end{array}$ & $\begin{array}{c}76+, \\
\mathrm{n}=73\end{array}$ & $\begin{array}{c}61+, \\
\mathrm{n}=209\end{array}$ \\
\hline Non-frail, $n(\%)$ & $302(71.1)$ & $40(29.4)$ & $22(15.1)$ & $51(24.4)$ \\
Pre-frail, $n(\%)$ & $111(26.1)$ & $58(42.7)$ & $36(49.3)$ & $114(54.7)$ \\
Frail, $n(\%)$ & $17(2.8)$ & $38(27.9)$ & $26(35.6)$ & $64(30.6)$ \\
\hline
\end{tabular}

mFI, Modified Frailty Index. peaks were noted for patients aged $61-75$, and $>75$ years. As a result, correlation analysis of variables on outcome was performed according to these age distributions.

\section{Frailty characteristics}

Frail patients were older (mean, 70.6 years [standard deviation (SD), 11.0] vs. mean, 42.0 years [SD, 17.5]; $p<0.0001$ ), had increased BMI (mean, 27.3 [SD, 4.2] vs. mean, 24.6 [SD, 4.0]; $p<$ $0.0001)$, and were more likely to have suffered their injury as a result of a fall versus transport or sports injury $(p<0.0001)$. Frail patients had higher incidence of high- and low-cervical injuries versus non-frail patients suffering thoracolumbar injuries $(p<$ $0.0001)$. Frail patients also displayed higher accumulation of deficits as per the CCI $(p<0.0001)$ and ECI $(p<0.0001)$, and as per comorbidity counts $(p<0.0001)$. Lastly, frail patients were more likely to have suffered a pneumonia $(p=0.0463)$, cardiac arrest/failure/arrythmia $(p=0.0373)$, or delirium $(p<0.0001)$ during their inpatient stay. 


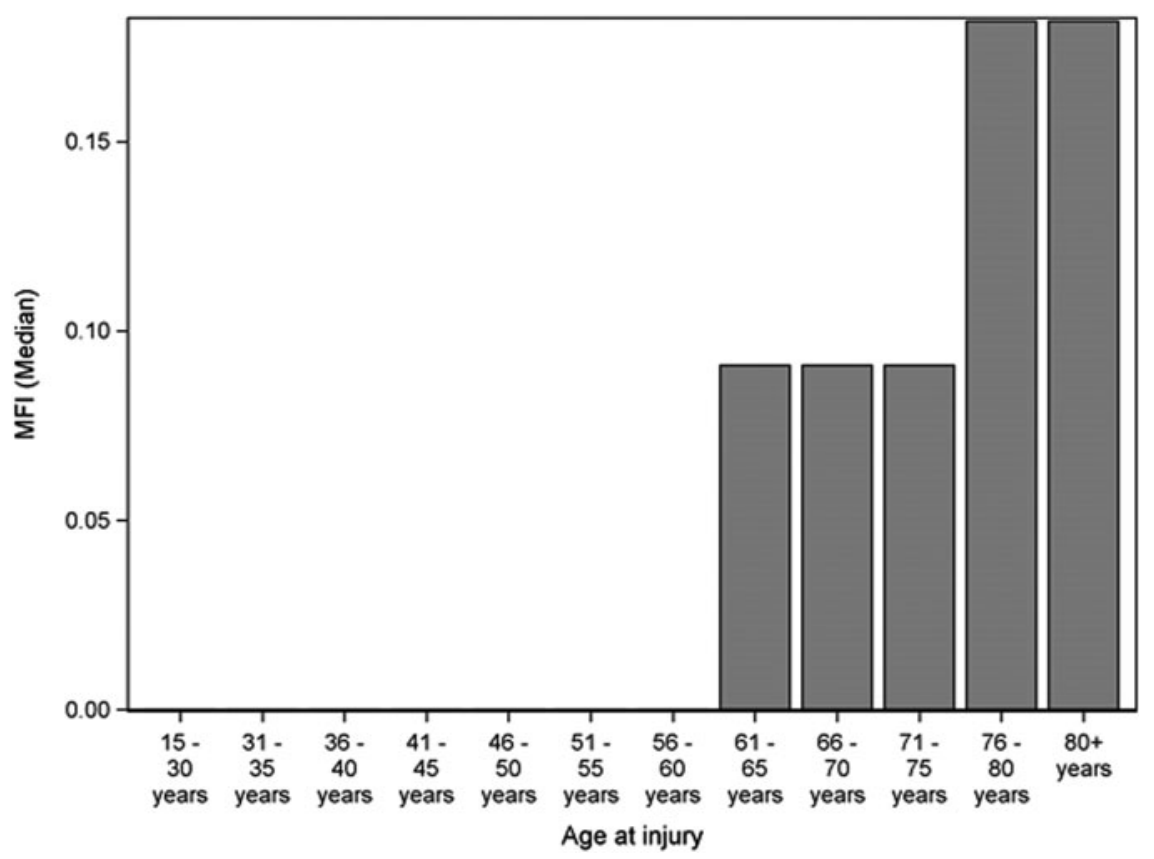

FIG. 1. Relationship between frailty and age at injury. MFI, Modified Frailty Index.

\section{Frailty on post-operative outcomes: Bivariate analysis}

mFI was a strong predictor of increased acute LOS (Pearson's $r=0.163 ; p<0.0001)$, number of AEs $(r=0.1664 ; p<0.0001)$, and in-hospital mortality $(r=0.155 ; p<0.0001)$ for the total cohort (Table 3 ). Age at injury was also significantly correlated with acute LOS $(r=0.0809 ; p=0.0418)$, number of AEs $(r=0.0937 ; p=$ $0.0231)$, and in-hospital mortality $(r=0.2639 ; p<0.0001)$. Lastly, motor score on admission was also predictive of acute LOS $(r=-0.4749 ; p<0.0001)$, number of AEs $(r=-0.3069 ; p<0.0001)$, and in-hospital mortality $(r=-0.2249 ; p<0.0001)$.

Subgroup analysis was then performed on patients aged $<60,61-$ 75 , and $>75$ years to investigate the complex relationship observed between age and frailty (Table 3 ). In patients aged $<60$ years, $\mathrm{mFI}$ was strongly predictive of acute LOS $(p=0.0045)$, number of AEs
( $p=0.0038)$, and in-hospital mortality $(p=0.0183)$. This was also true for motor score on admission, which was predictive of acute LOS $(p<0.0001)$, number of AEs $(p<0.0001)$, and in-hospital mortality $(p=0.0136)$. Age at injury was not predictive of outcomes in this age cohort.

In patients aged $61-75$ years, $\mathrm{mFI}$ was predictive of acute LOS $(p=0.0220)$, but not predictive of number of AEs or in-hospital mortality. TMS remained predictive of LOS $(p<0.0001)$, number of AEs $(p=0.0015)$, and in-hospital mortality $(p=0.0296)$. Age at time of injury was not predictive of any of the three outcomes.

For patients aged $>75$ years, age at injury was predictive of acute LOS $(p=0.0318)$ and number of AEs $(p=0.0009)$, but not inhospital mortality. TMS was predictive of $\operatorname{LOS}(p=0.0427)$ and inhospital mortality $(p<0.0001)$, but not number of AEs. Finally, $\mathrm{mFI}$ in this age cohort was not predictive of any outcome measure.

Table 3. Bivariate Analysis of Outcomes for Analysis Cohort $(N=634),<60$ Years $(N=425)$, 61-75 Years $(N=136)$, AND $76+$ Years $(N=73)$ COHORTS

\begin{tabular}{|c|c|c|c|c|c|c|c|c|c|}
\hline \multirow[b]{2}{*}{$\begin{array}{l}\text { Independent } \\
\text { variable }\end{array}$} & \multirow[b]{2}{*}{ Outcome } & \multicolumn{2}{|c|}{ Analysis cohort } & \multicolumn{2}{|c|}{$<60$ years } & \multicolumn{2}{|c|}{$61-75$ years } & \multicolumn{2}{|c|}{$76+$ years } \\
\hline & & $\begin{array}{c}\text { Correlation } \\
\text { coefficient }\end{array}$ & $\mathrm{P}$-value & $\begin{array}{c}\text { Correlation } \\
\text { coefficient }\end{array}$ & P-value & $\begin{array}{c}\text { Correlation } \\
\text { coefficient }\end{array}$ & $\mathrm{P}$-value & $\begin{array}{c}\text { Correlation } \\
\text { coefficient }\end{array}$ & P-value \\
\hline \multirow[t]{3}{*}{$\mathrm{mFI}$} & Acute LOS & 0.1630 & $<0.0001$ & 0.1377 & 0.0045 & 0.1962 & 0.0220 & 0.0642 & 0.5895 \\
\hline & Number of AEs & 0.1664 & $<0.0001$ & 0.1452 & 0.0038 & 0.1565 & 0.0789 & 0.1578 & 0.2056 \\
\hline & $\begin{array}{l}\text { In-hospital } \\
\text { mortality }\end{array}$ & 0.1550 & $<0.0001$ & 0.1144 & 0.0183 & 0.0745 & 0.3886 & -0.1321 & 0.2654 \\
\hline \multirow[t]{3}{*}{ Age at injury } & Acute LOS & 0.0809 & 0.0418 & 0.0432 & 0.3742 & 0.0431 & 0.6184 & -0.2516 & 0.0318 \\
\hline & Number of AEs & 0.0937 & 0.0231 & 0.0648 & 0.1988 & 0.1118 & 0.2109 & -0.3977 & 0.0009 \\
\hline & $\begin{array}{l}\text { In-hospital } \\
\text { mortality }\end{array}$ & 0.2639 & $<0.0001$ & 0.0083 & 0.8648 & 0.1452 & 0.0916 & 0.1363 & 0.2502 \\
\hline \multirow{3}{*}{$\begin{array}{l}\text { Motor score } \\
\text { at admission }\end{array}$} & Acute LOS & -0.4749 & $<0.0001$ & -0.4770 & $<0.0001$ & -0.5624 & $<0.0001$ & -0.2562 & 0.0427 \\
\hline & Number of AEs & -0.3069 & $<0.0001$ & -0.3538 & $<0.0001$ & -0.2920 & 0.0015 & 0.0188 & 0.8874 \\
\hline & $\begin{array}{l}\text { In-hospital } \\
\text { mortality }\end{array}$ & -0.2249 & $<0.0001$ & -0.1281 & 0.0136 & -0.1962 & 0.0296 & -0.5181 & $<0.0001$ \\
\hline
\end{tabular}

AE, adverse event; LOS, length of stay; mFI, Modified Frailty Index. 
Table 4. Multiple Linear Regression Analysis of Acute Length of Stay for the Analysis COHORT $(N=634)$

\begin{tabular}{lrcrrr}
\hline Parameter & Estimate & $\begin{array}{c}\text { Standard } \\
\text { error }\end{array}$ & $\begin{array}{c}\text { 95\% confidence } \\
\text { intervals }\end{array}$ & P-value \\
\hline Intercept & 3.9742 & 0.1048 & 3.7683 & 4.1800 & $<0.0001$ \\
Age at injury & 0.0000 & 0.0019 & -0.0038 & 0.0037 & 0.9832 \\
$\begin{array}{l}\text { Motor score } \\
\text { at admission }\end{array}$ & -0.0185 & 0.0010 & -0.0205 & -0.0165 & $<\mathbf{0 . 0 0 0 1}$ \\
mFI frail & 0.1594 & 0.1167 & -0.0699 & 0.3887 & 0.1727 \\
mFI pre-frail & 0.1955 & 0.0771 & 0.0440 & 0.3469 & $\mathbf{0 . 0 1 1 5}$ \\
mFI non-frail & Baseline & - & - & - & - \\
\hline
\end{tabular}

mFI, Modified Frailty Index.

Table 5. Negative Binomial Regression Analysis of Number of Adverse Events for the Analysis COHORT $(N=634)$

\begin{tabular}{|c|c|c|c|c|c|}
\hline Parameter & Estimate & $\begin{array}{c}\text { Standard } \\
\text { error }\end{array}$ & $\begin{array}{r}\text { Wald } \\
\text { confic } \\
\text { inter }\end{array}$ & $\begin{array}{l}95 \% \\
\text { dence } \\
\text { rvals }\end{array}$ & $\mathrm{P}$-value \\
\hline Intercept & 1.5154 & 0.1171 & 1.2858 & 1.7449 & $<0.0001$ \\
\hline Age at injury & 0.0027 & 0.0022 & -0.0016 & 0.0069 & 0.2186 \\
\hline $\begin{array}{l}\text { Motor score } \\
\text { at admission }\end{array}$ & -0.0096 & 0.0013 & -0.0120 & -0.0071 & $<0.0001$ \\
\hline mFI frail & 0.2379 & 0.1260 & -0.0091 & 0.4850 & 0.0591 \\
\hline $\mathrm{mFI}$ pre-frail & 0.0201 & 0.0867 & -0.1498 & 0.1900 & 0.8166 \\
\hline mFI non-frail & Baseline & . & & - & - \\
\hline
\end{tabular}

mFI, Modified Frailty Index.

\section{Frailty on post-operative outcomes: Multi-variable analysis}

Previous authors have subdivided patients into not frail $(\mathrm{mFI}=0)$, pre-frail $(0<\mathrm{mFI}<0.21)$, and frail $(\mathrm{mFI} \geq 0.21)$ categories. ${ }^{33}$ A similar division was made for our tSCI cohort, and association with outcome measures was explored.

Acute hospital LOS was significantly different between frailty categories ( $p=0.0134$; Table 4$)$ when controlling for the covariates, the $\mathrm{mFI}$ was a significant predictor of $\operatorname{LOS}(p=0.0375)$, with the pre-frail group having a significantly longer LOS $(p=0.0115)$ when compared with the non-frail group.

When unadjusted for other covariates, significant differences exist between all three frailty categories $(p=0.0375)$ in terms of median number of AEs. After adjusting for age at time of injury and TMS on admission, the mFI was not a significant predictor for number of AEs; however, the frail group tended to be more likely to experience an increased number of AEs compared with the nonfrail group ( $p=0.0591)$ (Table 5).

In-hospital mortality was significantly different between frailty categories $(p<0.0001)$, with non-frail patients being more likely to survive. However, in multi-variable analysis, age and motor score at admission were predictors of in-hospital mortality, whereas $\mathrm{mFI}$ was not $(p=0.1245)$ (Table 6).

Discharge destination was grouped into either discharge home, or discharge to a different destination (e.g., long-term care facility; Table 7). A significantly larger proportion of patients with no frailty were discharged home as compared with other frailty categories $(p=0.0315)$. After adjusting for age and motor score on admission mFI was no longer predictive of discharge destination $(p=0.5062)$. Of note, TMS at admission is strongly predictive of discharge destination on its own.

\section{Discussion}

Our study has identified frailty as a risk factor for poor postoperative outcomes in a tSCI patient population, in keeping with previous findings. First described in an intensive care unit (ICU) setting, Fried and colleagues defined frailty as "a clinical picture of loss of physiological and cognitive functioning which leaves patients susceptible to significant deterioration often precipitated by relatively minor stressors, such as infection, surgery, or trauma." ${ }^{, 34}$ With reference to a surgical setting specifically, frailty has been shown to affect post-operative outcomes in multiple specialties, ${ }^{35,36}$ disproportionately affecting in-hospital and longterm mortality, and discharge destination. ${ }^{37}$

With regard to spine surgery, most studies have similarly linked frailty and worsened post-operative outcomes, mortality, and discharge disposition. ${ }^{38,39}$ Flexman and associates showed higher complication rates, specifically with infection, in a population of elective degenerative spine patients. ${ }^{33}$ Ali and co-workers reviewed the 18,294 patients in the National Surgery Quality Improvement Program (NSQIP) database who had undergone spine surgery. ${ }^{40}$ Similar to our own work, this group divided the $\mathrm{mFI}$ into low $(<2.7)$ and high $(\geq 2.7)$ categories, and noted a substantial difference in infection $(1.7 \%$ vs. $4.1 \%)$ and mortality $(0.1 \%$ vs. $2.3 \%)$ rates. ${ }^{40}$ In an adult spinal deformity population, Miller and colleagues noted increased risk of junctional kyphosis (odds ratio [OR] 2.8), pseudarthrosis (OR 13.0), deep wound infection (OR 8.0), and wound dehiscence (OR 13.4) as compared with non-frail patients. ${ }^{41}$ A recent systematic review of the literature found that despite discrepancies in measurement tools, frailty is a consistent predictor of mortality, minor and major morbidity, in-hospital LOS, and discharge disposition in patients undergoing spine surgery. ${ }^{42}$

Traditionally, however, frailty is a concept that has been intimately linked with older age. ${ }^{43}$ Bagshaw and associates were among the first groups to note that the prevalence of frailty in younger

Table 6. Multiple Logistic Regression Analysis of In-Hospital Mortality for the Analysis Cohort ( $N=634)$

\begin{tabular}{|c|c|c|c|c|c|c|}
\hline Parameter & Estimate & Standard error & Odds ratio & \multicolumn{2}{|c|}{ 95\% confidence interval } & $\mathrm{P}$-value \\
\hline Intercept & -6.6591 & 1.2529 & - & - & - & $<0.0001$ \\
\hline Age at injury & 0.0790 & 0.0190 & 1.0820 & 1.0430 & 1.1230 & $<0.0001$ \\
\hline Motor score at admission & -0.0447 & 0.0106 & 0.9560 & 0.9370 & 0.9760 & $<0.0001$ \\
\hline mFI frail & 0.9089 & 0.5917 & 2.4810 & 0.7780 & 7.9130 & 0.1245 \\
\hline mFI pre-frail & -0.4829 & 0.6107 & 0.6170 & 0.1860 & 2.0420 & 0.4291 \\
\hline mFI non-frail & Baseline & - & - & - & - & - \\
\hline
\end{tabular}

mFI, Modified Frailty Index. 
Table 7. Multiple Logistic Regression Analysis of Discharge to Home Including Frailty Status (Frail: mFI $>0.21$, $N=76$; Non-Frail: $\mathrm{mFI} \leq 0.21, N=353)$ For the ANAlysis Cohort $(N=634)$

\begin{tabular}{|c|c|c|c|c|c|c|}
\hline Parameter & Estimate & Standard error & Odds ratio & \multicolumn{2}{|c|}{$95 \%$ confidence interval } & $\mathrm{P}$-value \\
\hline Intercept & -6.6305 & 0.7631 & - & - & - & $<0.0001$ \\
\hline Age at injury & -0.0117 & 0.00975 & 0.988 & 0.970 & 1.007 & 0.2306 \\
\hline Motor score at admission & 0.0840 & 0.0088 & 1.088 & 1.069 & 1.107 & $<0.0001$ \\
\hline mFI frail & -0.4093 & 0.6157 & 0.664 & 0.199 & 2.220 & 0.5062 \\
\hline mFI pre-frail & -0.5799 & 0.3700 & 0.5600 & 0.271 & 1.156 & 0.1171 \\
\hline mFI non-frail & Baseline & - & - & - & - & - \\
\hline
\end{tabular}

mFI, Modified Frailty Index.

patients is not only underappreciated, but perhaps especially damaging. ${ }^{44}$ According to Smart and co-workers, this phenomenon of frailty in the young becomes particularly important in a surgical emergency scenario. ${ }^{45}$ Although it is clear that the aging process is a contributor, there are many other patient and environmental factors that can drain physiological reserve in response to stressors. ${ }^{46}$

In our study, frailty was predictive of poor outcome in the entire cohort, but not in the subgroup of the most elderly ( $\geq 75$ years). As a result, we can conclude that there must exist a more complex relationship between age and frailty than is noted in previous studies. Our work also implies that younger, "frail" individuals are likely at particular risk for AEs, complications, and death as compared with their young, non-frail counterparts. In a tSCI population, when an individual is faced with such a devastating injury after reaching a certain age, physiological reserve likely loses its importance.

To our knowledge, no current work has looked at frailty in a tSCI cohort. Of note, our tSCI population had a much higher degree of frailty than other studied populations. In a cohort of patients over the age of 65 years undergoing elective surgery for degenerative conditions of the lumbar spine, modified frailty score was 0.09 , with $59.8 \%$ being not frail, $20.6 \%$ pre-frail, and $19.6 \%$ frail. ${ }^{38}$ In our cohort of patients over the age of 61 years, $30.6 \%$ were frail. When comparing the tSCI population with the elective surgery cohort, despite having a lower age limit of 61 versus 65 years, frailty is 1.5 times more common. ${ }^{38}$ This difference is striking, particularly as the main cause of injury is through falls in our cohort, which may occur in more frail individuals. With the increase in the older population, this problem will likely be exacerbated and should be considered in future planning.

Multiple measures of frailty are used in research and published in the literature, and simplified measures such as the mFI and Charlson and Elixhauser comorbidity indexes are not nuanced enough to capture important physiological changes that underpin the multi-dimensional concept of frailty, such as nutritional status, cognitive impairment, and poor performance status. ${ }^{42}$ Additionally, cutoff frailty values as used in this and other studies may not apply to tSCI. The insult of the tSCI itself may be so great that it may affect outcomes to a higher degree than values currently used.

The strengths of our study include its large sample and the robust nature of our database. The benefits of the SAVES reporting system have been outlined in our previous work. ${ }^{47}$ Data were gathered from a single institution, and may not accurately reflect the experience of other centers. Due to varying definitions, our selection of a threshold value for mFI may not be directly applicable to other published reports.

\section{Conclusions}

The link between frailty, the aging process, and poor postoperative outcomes has been well-established through research.
When faced with an injury as physiologically taxing as a tSCI, however, the effect of deficit accumulation loses importance. This work will aid in surgical decision-making and risk stratification in tSCI patients. Future efforts should be directed toward the identification of a more accurate tool for measurement of frailty in the elderly, as well as toward finding in a younger population specific risk factors contributing to poor outcomes.

\section{Author Disclosure Statement}

No competing financial interests exist.

\section{References}

1. Iqbal, J., Denvir, M., and Gunn, J. (2013). Frailty assessment in elderly people. Lancet $381,1985-1986$.

2. Partridge, J.S.L., Harari, D., and Dhesi, J.K. (2012). Frailty in the older surgical patient: a review. Age Ageing 41, 142-147.

3. Fried, L.P., Tangen, C.M., Walston, J., Newman, A.B., Hirsch, C., Gottdiener, J., Seeman, T., Tracy, R., Kop, W.J., Burke, G., McBurnie, M.A., and Cardiovascular Health Study Collaborative Research Group. (2001). Frailty in older adults: evidence for a phenotype. J. Gerontol. A. Biol. Sci. Med. Sci. 56, M146-M156.

4. Fhon, J.R.S., Rodrigues, R.A.P., Santos, J.L.F., Diniz, M.A., Santos, E.B., Dos, Almeida, V.C., and Giacomini, S.B.L. (2018). Factors associated with frailty in older adults: a longitudinal study. Rev. Saude Publica 52, 74.

5. Donald, G.W., Ghaffarian, A.A., Isaac, F., Kraiss, L.W., Griffin, C.L., Smith, B.K., Sarfati, M.R., Beckstrom, J.L., and Brooke, B.S. (2018). Preoperative frailty assessment predicts loss of independence after vascular surgery. J. Vasc. Surg. 68, 1382-1389.

6. Karam, J., Tsiouris, A., Shepard, A., Velanovich, V., and Rubinfeld, I. (2013). Simplified frailty index to predict adverse outcomes and mortality in vascular surgery patients. Ann. Vasc. Surg. 27, 904-908.

7. Kim, S., Han, H.-S., Jung, H., Kim, K., Hwang, D.W., Kang, S.-B., and Kim, C.-H. (2014). Multidimensional frailty score for the prediction of postoperative mortality risk. JAMA Surg. 149, 633.

8. Makary, M.A., Segev, D.L., Pronovost, P.J., Syin, D., Bandeen-Roche, K., Patel, P., Takenaga, R., Devgan, L., Holzmueller, C.G., Tian, J., and Fried, L.P. (2010). Frailty as a predictor of surgical outcomes in older patients. J. Am. Coll. Surg. 210, 901-908.

9. Velanovich, V., Antoine, H., Swartz, A., Peters, D., and Rubinfeld, I. (2013). Accumulating deficits model of frailty and postoperative mortality and morbidity: its application to a national database. J. Surg. Res. 183, 104-110.

10. McIsaac, D.I., Taljaard, M., Bryson, G.L., Beaulé, P.E., Gagné, S., Hamilton, G., Hladkowicz, E., Huang, A., Joanisse, J.A., Lavallée, L.T., MacDonald, D., Moloo, H., Thavorn, K., van Walraven, C., Yang, H., and Forster, A.J. (2018). Frailty as a predictor of death or new disability after surgery. Ann. Surg. doi: 10.1097/SLA.0000000000002967 [Epub ahead of print].

11. Joseph, B., Zangbar, B., Pandit, V., Fain, M., Mohler, M.J., Kulvatunyou, N., Jokar, T.O., O'Keeffe, T., Friese, R.S., and Rhee, P. (2016). Emergency general surgery in the elderly: too old or too frail? J. Am. Coll. Surg. $222,805-813$.

12. McIsaac, D.I., Moloo, H., Bryson, G.L., and van Walraven, C. (2017). The association of frailty with outcomes and resource use after emergency general surgery. Anesth. Analg. 124, 1653-1661. 
13. Flexman, A.M., Charest-Morin, R., Stobart, L., Street, J., and Ryerson, C.J. (2016). Frailty and postoperative outcomes in patients undergoing surgery for degenerative spine disease. Spine J. 16, 1315-1323.

14. Mitnitski, A.B., Graham, J.E., Mogilner, A.J., and Rockwood, K. (2002). Frailty, fitness and late-life mortality in relation to chronological and biological age. BMC Geriatr. 2, 1.

15. Mitnitski, A.B., Mogilner, A.J., and Rockwood, K. (2001). Accumulation of deficits as a proxy measure of aging. Sci. World J. 1, 323-336.

16. Ahn, H., Bailey, C.S., Rivers, C.S., Noonan, V.K., Tsai, E.C., Fourney, D.R., Attabib, N., Kwon, B.K., Christie, S.D., Fehlings, M.G., Finkelstein, J., Hurlbert, R.J., Townson, A., Parent, S., Drew, B., Chen, J., and Dvorak, M.F. (2015). Effect of older age on treatment decisions and outcomes among patients with traumatic spinal cord injury. CMAJ 187, 873-880.

17. Ahn, H., Lewis, R., Santos, A., Cheng, C.L., Noonan, V.K., Dvorak, M.F., Singh, A., Linassi, A.G., Christie, S., Goytan, M., and Atkins, D. (2017). Forecasting financial resources for future traumatic spinal cord injury care using simulation modeling. J. Neurotrauma 34, 2917-2923.

18. van den Berg, M.E.L., Castellote, J.M., Mahillo-Fernandez, I., and de Pedro-Cuesta, J. (2010). Incidence of spinal cord injury worldwide: a systematic review. Neuroepidemiology 34, 184-192.

19. Furlan, J.C., Noonan, V., Singh, A., and Fehlings, M.G. (2011). Assessment of disability in patients with acute traumatic spinal cord injury: a systematic review of the literature. J. Neurotrauma 28, 1413-1430.

20. Seel, R.T., Huang, M.E., Cifu, D.X., Kolakowsky-Hayner, S.A., and McKinley, W.O. (2001). Age-related differences in length of stays, hospitalization costs, and outcomes for an injury-matched sample of adults with paraplegia. J. Spinal Cord Med. 24, 241-250.

21. Smith, S., Purzner, T., and Fehlings, M. (2010). The epidemiology of geriatric spinal cord injury. Top. Spinal Cord Inj. Rehabil. 15, 54-64.

22. Schneider, R.C., Cherry, G., and Pantek, H. (1954). The syndrome of acute central cervical spinal cord injury. J. Neurosurg. 11, 546-577.

23. Krassioukov, A.V, Furlan, J.C., and Fehlings, M.G. (2003). Medical co-morbidities, secondary complications, and mortality in elderly with acute spinal cord injury. J. Neurotrauma 20, 391-400.

24. Liang, H.W., Wang, Y.H., Lin, Y.N., Wang, J.D., and Jang, Y. (2001). Impact of age on the injury pattern and survival of people with cervical cord injuries. Spinal Cord 39, 375-380.

25. Noonan, V.K., Kwon, B.K., Soril, L., Fehlings, M.G., Hurlbert, R.J., Townson, A., Johnson, M., and Dvorak, M.F. (2012). The Rick Hansen Spinal Cord Injury Registry (RHSCIR): a national patientregistry. Spinal Cord 50, 22-27.

26. Charlson, M., Pompei, P., Ales, K., and MacKenzie, R. (1987). A new method of classifying prognostic comorbidity in longitudinal studies: development and validation. J. Chronic Dis. 40, 373-383.

27. Elixhauser, A., Steiner, C., Harris, D.R., and Coffey, R.M. (1998). Comorbidity measures for use with administrative data. Med. Care 36, $8-27$.

28. Rockwood, K., Song, X., and Mitnitski, A. (2011). Changes in relative fitness and frailty across the adult lifespan: evidence from the Canadian National Population Health Survey. CMAJ 183, E487-E494.

29. Biering-Sørensen, F., DeVivo, M.J., Charlifue, S., Chen, Y., New, P.W., Noonan, V., Post, M.W.M., and Vogel, L. (2017). International Spinal Cord Injury Core Data Set (version 2.0)—including standardization of reporting. Spinal Cord 55, 759-764.

30. Waring, W.P., Biering-Sorensen, F., Burns, S., Donovan, W., Graves, D., Jha, A., Jones, L., Kirshblum, S., Marino, R., Mulcahey, M.J., Reeves, R., Scelza, W.M., Schmidt-Read, M., and Stein, A. (2010). 2009 review and revisions of the International Standards for the Neurological Classification of Spinal Cord Injury. J. Spinal Cord Med. 33, 346-352.

31. Street, J.T., Lenehan, B.J., DiPaola, C.P., Boyd, M.D., Kwon, B.K., Paquette, S.J., Dvorak, M.F., Rampersaud, Y.R., and Fisher, C.G. (2012). Morbidity and mortality of major adult spinal surgery. a prospective cohort analysis of 942 consecutive patients. Spine J. 12, 22-34.

32. Rampersaud, Y.R., Neary, M.A., and White, K. (2010). Spine adverse events severity system: content validation and interobserver reliability assessment. Spine (Phila. Pa. 1976) 35, 790-795.

33. Flexman, A.M., Charest-Morin, R., Stobart, L., Street, J., and Ryerson, C.J. (2016). Frailty and postoperative outcomes in patients undergoing surgery for degenerative spine disease. Spine J. 16, 1315-1323.
34. Fried, L.P., Ferrucci, L., Darer, J., Williamson, J.D., and Anderson, G. (2004). Untangling the concepts of disability, frailty, and comorbidity: implications for improved targeting and care. J. Gerontol. A. Biol. Sci. Med. Sci. 59, 255-263.

35. Mosquera, C., Spaniolas, K., and Fitzgerald, T.L. (2016). Impact of frailty on surgical outcomes: the right patient for the right procedure. Surgery $160,272-280$

36. Anand, A., Harley, C., Visvanathan, A., Shah, A.S.V., Cowell, J., MacLullich, A., Shenkin, S., and Mills, N.L. (2017). The relationship between preoperative frailty and outcomes following transcatheter aortic valve implantation: a systematic review and meta-analysis. Eur. Heart J. Qual. Care Clin. Outcomes 3, 123-132.

37. Muscedere, J., Waters, B., Varambally, A., Bagshaw, S.M., Boyd, J.G., Maslove, D., Sibley, S., and Rockwood, K. (2017). The impact of frailty on intensive care unit outcomes: a systematic review and metaanalysis. Intensive Care Med. 43, 1105-1122.

38. Charest-Morin, R., Street, J., Zhang, H., Roughead, T., Ailon, T., Boyd, M., Dvorak, M., Kwon, B., Paquette, S., Dea, N., Fisher, C.G., and Flexman, A.M. (2018). Frailty and sarcopenia do not predict adverse events in an elderly population undergoing non-complex primary elective surgery for degenerative conditions of the lumbar spine. Spine J. 18, 245-254.

39. Ahmed, A.K., Goodwin, C.R., De la Garza-Ramos, R., Kim, R.C., Abu-Bonsrah, N., Xu, R., and Sciubba, D.M. (2017). Predicting shortterm outcome after surgery for primary spinal tumors based on patient frailty. World Neurosurg. 108, 393-398.

40. Ali, R., Schwalb, J.M., Nerenz, D.R., Antoine, H.J., and Rubinfeld, I. (2016). Use of the modified frailty index to predict 30-day morbidity and mortality from spine surgery. J. Neurosurg. Spine 25, 537-541.

41. Miller, E.K., Neuman, B.J., Jain, A., Daniels, A.H., Ailon, T., Sciubba, D.M., Kebaish, K.M., Lafage, V., Scheer, J.K., Smith, J.S., Bess, S., Shaffrey, C.I., Ames, C.P., and International Spine Study Group. (2017). An assessment of frailty as a tool for risk stratification in adult spinal deformity surgery. Neurosurg. Focus 43, E3.

42. Moskven, E., Bourassa-Moreau, É., Charest-Morin, R., Flexman, A., and Street, J. (2018). The impact of frailty and sarcopenia on postoperative outcomes in adult spine surgery. A systematic review of the literature. Spine J. 18, 2354-2369.

43. Lin, H.-S., Watts, J.N., Peel, N.M., and Hubbard, R.E. (2016). Frailty and post-operative outcomes in older surgical patients: a systematic review. BMC Geriatr. 16, 157.

44. Bagshaw, M., Majumdar, S.R., Rolfson, D.B., Ibrahim, Q., Mcdermid, R.C., and Stelfox, H.T. (2016). A prospective multicenter cohort study of frailty in younger critically ill patients. Crit. Care 20, 175.

45. Smart, R., Carter, B., McGovern, J., Luckman, S., Connelly, A., Hewitt, J., Quasim, T., and Moug, S. (2017). Frailty Exists in Younger Adults Admitted as Surgical Emergency Leading to Adverse Outcomes. J. Frailty Aging 6, 219-223.

46. Smitherman, A.B., Anderson, C., Lund, J.L., Bensen, J.T., Rosenstein, D.L., and Nichols, H.B. (2018). Frailty and comorbidities among survivors of adolescent and young adult cancer: a cross-sectional examination of a hospital-based survivorship cohort. J. Adolesc. Young Adult Oncol. 7, 374-383.

47. Street, J.T., Thorogood, N.P., Cheung, A., Noonan, V.K., Chen, J., Fisher, C.G., and Dvorak, M.F. (2013). Use of the Spine Adverse Events Severity System (SAVES) in patients with traumatic spinal cord injury. A comparison with institutional ICD-10 coding for the identification of acute care adverse events. Spinal Cord 51, 472-476.

Address correspondence to: John T. Street MD, PhD, FRCSI Combined Neurosurgical and Orthopaedic Spine Program Department of Orthopaedic Surgery University of British Columbia Vancouver Spine Surgery Institute Blusson Spinal Cord Center 818 West 10th Avenue Vancouver, British Columbia V5Z 1M9 Canada

E-mail: john.street@vch.ca 